
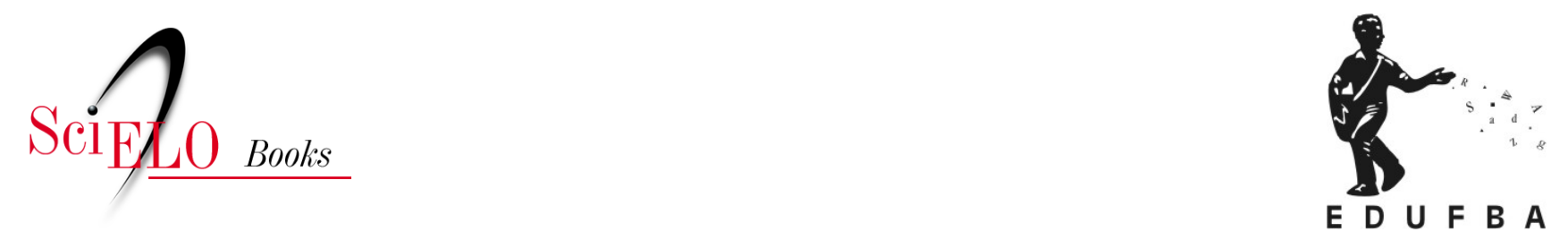

\title{
Reflexões sobre escolhas alimentares de nutricionistas com obesidade
}

\author{
Kênya Lima Araújo \\ Paulo Gilvane Lopes Pena \\ Maria do Carmo Soares de Freitas
}

\section{SciELO Books / SciELO Livros / SciELO Libros}

ARAÚJO, K.L., PENA, P.G.L., and FREITAS, M.C.S. Reflexões sobre escolhas alimentares de nutricionistas com obesidade. In: LIMA, M.A.G., FREITAS, M.C.S., PENA, P.G.L., and TRAD, S., orgs. Estudos de saúde, ambiente e trabalho: aspectos socioculturais [online]. Salvador: EDUFBA, 2017, pp. 109-124. ISBN: 978-85-232-1864-5. http://doi.org/10.7476/9788523218645.0005

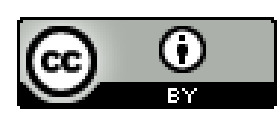

All the contents of this work, except where otherwise noted, is licensed under a Creative Commons Attribution $\underline{4.0 \text { International license. }}$

Todo o conteúdo deste trabalho, exceto quando houver ressalva, é publicado sob a licença $\underline{\text { Creative Commons }}$ Atribição 4.0. 


\section{Reflexões sobre escolhas alimentares de nutricionistas com obesidade}

KÊNYA LIMA ARAÚJO

PAULO GILVANE LOPES PENA

MARIA DO CARMO SOARES DE FREITAS

\section{Introdução}

De acordo com a Organização Munidal de Saúde (OMS) quase 2 bilhões de adultos em todo o mundo estão com excesso de peso, e destes $11 \%$ dos homens e $15 \%$ das mulheres são obesos. (WHO, [201-]) A "globosidade" tem sido um desafio para a saúde em todo o mundo - o que põe em relevo a exigência de pensar sobre ela.

O Ministério da Saúde do Brasil através da pesquisa "Vigilância de Fatores de Risco e Proteção para Doenças Crônicas por Inquérito Telefônico" (VIGITEL) evidenciou que mais da metade da população adulta do país (52,3\%) está com excesso de peso. (BRASIL, 2017) O cenário epidemiológico apresenta a gravidade deste estado de morbidade e a necessidade de discutir esse fenômeno que tem se mostrado difícil de ser superado.

Alguns elementos como comportamentos individuais, condições de vida e trabalho, e aspectos sociais relacionados à economia, educação e cultura podem ajudar a compreender o estado de saúde dos sujeitos. (CNDSS, 
2006) Nesse sentido, importa pensar o ambiente como modulador da saúde das pessoas, tanto no campo biológico, através de influência na expressão epigenética, quanto no tocante aos hábitos de vida - alimentação cotidiana e prática de atividade física regular, p.e., refletindo o peso corporal como resposta da condição de saúde. (BADZIAK; MOURA, 2010)

Aspectos que tocam a condição de vida e saúde dos sujeitos foram indicados como potenciais fatores obesogênicos em uma sociedade. O termo "obesogênico" foi inaugurado a partir de hipóteses sugeridas por Bruce Blumberg, pesquisador da Universidade da Califórnia, nos estudos relacionados a perturbadores endócrinos ambientais.

Nesse entendimento, vale considerar as reflexões de Bourdieu (1989) sobre habitus, que, para ele, revela um modo de ver e sentir o mundo. E nesta perspectiva, o cotidiano dos sujeitos, sua experiência social, referências do comer tendem a refletir as escolhas alimentares com base na cultura a qual pertence. Há um modo de comer que é aprendido, que marca sua vivência na sociedade, que sedimenta seu gosto e institui suas preferências.

A cultura se inscreve no processo alimentar dos humanos, com escolhas influenciadas pela forma como as pessoas veem e sentem o mundo. Escolhe-se o alimento e a quantidade. Comer moderadamente ou excessivamente. Também, quando se escolhe o que comer nem sempre se prioriza o consumo de nutrientes, mas a dimensão simbólica do alimento. O que este representa para si. Então, mudar hábitos alimentares significa mudar símbolos, representações. (CONTRERAS, 2011)

A mudança de comportamento alimentar é difícil. Pressupõe mudanças sociais e, no contexto do hábito, transformações nas relações estabelecidas entre tempo, alimentação e gosto. Nesse debate, ao recorrer à socioantropologia da alimentação, poderia afirmar que em cada sociedade há práticas alimentares com regras e significados que produzem sentidos de pertencimento e identidade. (CONTRERAS, 2011) Por esta razão, não é possível desprezar estes aspectos socioculturais para não ocorrer uma quebra no entendimento das diversas dimensões do ato de se alimentar. (FREITAS; MINAYO; FONTES, 2011)

$\mathrm{Na}$ área da saúde, o pensamento cartesiano limita a chance de compreensão sobre a associação entre dietética e sociedade. Como uma ruptura, a visão mecanicista reduz as ações desses profissionais de saúde. (MOTTA, D.; MOTTA, C.; CAMPOS, 2012) Em geral, a dietética torna-se prescrita 
e deficiente na correspondência com a cultura do paciente. No plano real, fora de conjecturas dualistas e fechadas, observa-se que a nutricionista portadora de obesidade vive esse conflito na "pele”: a contradição entre teoria e prática do cuidado de si.

Para o campo da saúde, a expressão “alimentação saudável” indica uma diretriz para a prevenção de doenças e também tende à associação com uma imagem corporal delgada para aqueles que a ela façam adesão. (SILVA, 2012) Ademais, para as nutricionistas desse olhar, serão, sobretudo, as normas técnicas que regem a alimentação saudável. Normas que se traduzem em cotas ideais de nutrientes, como uma ração essencial para a vida e a saúde.

A Resolução 380/2005 do Conselho Federal de Nutricionistas (CFN) trata das atribuições desse profissional na perspectiva da promoção de práticas alimentares saudáveis, ao tempo em que a Política Nacional de Alimentação e Nutrição (PNAN) propõe a adoção de estratégias para a prevenção da obesidade e outras doenças crônicas não transmissíveis - diabetes, hipertensão, outras cardiovasculares. (BRASIL, 2012; CFN, 2006)

As políticas públicas e programas governamentais no país (BRASIL, 2006, 2009, 2010, 2012) referenciam os profissionais especializados - nutricionistas, educadores físicos, médicos, psicólogos - para o cuidado de pessoas com excesso de peso.

A formação profissional do nutricionista impõe a racionalidade científica como possibilidade de aplicação técnica determinante para o controle e tratamento da obesidade. (LUZ, 2004) Normas dietéticas relacionadas a adequações do balanço energético são estratégias prioritárias na terapêutica indicada aos sujeitos com obesidade. $\mathrm{O}$ alimento é dissecado em nutrientes e valor calórico para definição de prescrições dietéticas. A dimensão simbólica do alimento é desconstruída nesta racionalidade.

A doença, enquanto desordem metabólica, requer intervenção especializada. Mas nessa concepção biomédica, o profissional de saúde em geral desconsidera o sujeito e seus valores sociais. Para uma imersão no campo compreensivo da saúde, Freitas, Minayo e Fontes (2011) e a leitura de Gadamer $(2006,2015)$ nos auxiliou na possibilidade de entender que esse é um tema que requer profundidade sobre o sentido de ser no mundo. Nessa dimensão, este estudo tenta colar a imagem e os significados desse problema para o sujeito que a representa. Dessa maneira, cuidar da saúde requer o re- 
conhecimento de um sujeito que discorre sobre sua obesidade cuja abertura de mundo o situa em seu universo sociocultural.

Sobre isso, recorda-se o estudo de Denise Silva (2012, p. 169) que discute a experiência do profissional de saúde na promoção da alimentação saudável como um conflito entre "o imponderável humano" versus "o conhecimento científico" na determinação da sua práxis. Enfatiza a importância de agregar ao conhecimento técnico científico a dimensão sociocultural do sujeito para compreender suas escolhas alimentares.

Dessa configuração, pensar a obesidade de nutricionistas é um convite a discutir suas escolhas alimentares inadequadas, seu sedentarismo, sua adaptação e compreensão sobre esse problema de saúde.

Para tanto, o estudo contempla narrativas de nutricionistas com obesidade em cuja experiência pessoal e profissional demonstram o conflito em associar conhecimento técnico cientifico e escolhas alimentares no cotidiano. Sobre esta problemática, observa-se a importância de destacar a cultura obesogênica e a luta interna desses personagens reais que vivenciam o conflito de serem gordos e profissionais da alimentação.

\section{Metodologia}

Contemplam-se informações da dissertação de mestrado da principal autora cuja pesquisa qualitativa foi realizada em espaços de trabalhos de nutricionistas obesas na cidade de Salvador, Bahia, no ano de 2014. Foram critérios de inclusão: profissão nutricionista, sexo feminino, ser e sentir-se obesa. Trata-se, pois, de um estudo que discute a obesidade e sua interferência na vida socioprofissional destas mulheres.

As nutricionistas entrevistadas indicaram outras colegas, constituindo uma seleção para a pesquisa, contando com a similaridade entre seus discursos. Buscou-se conhecer as escolhas alimentares e seus significados, na tentativa de compreender como estas mulheres interpretam sua obesidade frente às atuais demandas biosocioculturais e entre estas, o recorrente preconceito contra esta enfermidade no tecido social - o estigma. (GOFFMAN, 1993) Para uma análise minudente da interpretação das narrativas produzidas, buscou-se a leitura de Hans-George Gadamer: Verdade e Método, 2015, parágrafos 400-619, que tratam da compreensão e da interpretação das falas.

São destacadas entrevistas narrativas, realizadas com sete nutricionistas e para tanto, seguiu-se um roteiro de questões mínimas, valorizando-se 
fragmentos de suas histórias de vida (BERTAUX, 1993; TODOROV, 2013), suas escolhas alimentares e a percepção da condição de indivíduos portadores de obesidade. Seus nomes foram preservados, utilizando-se apenas fictícios, conforme acordado com elas.

Ao buscar o cotidiano do comer tão próximo, volta-se a atenção para o uso dos termos, obeso e gordo neste estudo, considerados sinônimos e que representam a linguagem ética das ciências naturais e êmica, própria do mundo pessoal e cotidiano, portanto sociocultural. O conflito entre o técnico-científico da formação da nutricionista e o cultural aparece como central neste estudo polissêmico sobre a obesidade na profissional de saúde.

A pesquisa foi aprovada pelo Comitê de Ética em Pesquisa da Faculdade de Medicina da Universidade Federal da Bahia (CEP/FMB/UFBA) em 4 de setembro de 2013 sob o n 383.530. Considerou-se a Resolução 466/12 do Conselho Nacional de Saúde (CNS).

\section{Resultados e discussão}

As mulheres entrevistadas contaram sobre a forma velada com que a sociedade lhes responsabiliza pelo corpo obeso sem considerar a dimensão sociocultural e seus ambientes de trabalho, que lhes impõem uma carga laboral extenuante e incompatível com a saúde.

As narrativas revelam suas tentativas de modelagem da vida e do corpo para atender ao padrão físico e alimentar socialmente esperado em função da autorização científica que lhes é conferida pela formação acadêmica, e a influência da subjetividade rompendo com essa lógica.

Ao discutir a dicotomia existente entre teoria e prática no contexto das mudanças alimentares, observa-se um desafio do modelo explicativo, dado a pluralidade de significantes culturais entrelaçados nesse campo temático da alimentação, como: hábitos, conduta, comportamento e escolhas. (DIEZ-GARCIA, 2012) A realidade dos sujeitos deste estudo mostra "escolhas alimentares" como a expressão compartilhada entre as protagonistas, para significar esse fenômeno sociocultural, do qual se sentem prisioneiras.

\section{Influência da família na formação dos hábitos alimentares}

A experiência dos sujeitos em seu mundo social desde a infância delineia-se sobre escolhas alimentares cotidianas que nutrem o corpo biológico e 
o sociocultural. As nutricionistas revelam seus hábitos alimentares resultantes de uma aprendizagem que se iniciou na infância e foi consolidada no contexto familiar:

Educação alimentar tem que vir muito cedo. E eu não tive isso. A culpa (da obesidade) é da minha família, de minha mãe. [...] Quando era criança, se eu chorasse ela dizia: tome aqui um chocolate! [...] E a culpa é minha também. Eu poderia ter mudado essa realidade e estar com uma dieta de $1.200 \mathrm{Kcal}$. Mas a verdade é que não aguento. Hoje eu não posso fazer essa dieta. (Beatriz, 30 anos)

A família, entendida por Beatriz, como a instância de referência de cuidado, assume o lugar da falta de apoio materno no que concerne à alimentação. Na sua experiência a expressão do afeto se dá com a oferta de doces.

A mãe aparece como a pessoa que acolhe o choro com guloseimas, ao tempo que gera um problema que se fará presente até a vida adulta, gerando nesta nutricionista o sofrimento por não conseguir romper com o aprendizado de comer de um modo não saudável. No lugar mais íntimo da sua vida, na sua base, no espaço familiar, Beatriz vê sedimentar a sua obesidade.

Esta autora relata uma vida marcada por rupturas entre o desejo de ser aceita, valorizada, respeitada e cuidada e suas possibilidades de responder às necessidades de mudança do hábito alimentar que lhe é exigido para ocupar esse lugar.

A narradora entende seu problema como uma dificuldade que aparece na infância com a mãe, a qual a condicionou a um modo de se alimentar que não consegue transgredir, mesmo com o conhecimento científico de que dispõe.

Vale frisar que seria importante uma análise mais profunda com o auxílio da psicologia, mas neste estudo, assinala-se um breve entendimento da obesidade sem adentrar singularidades no campo psíquico. Em contrapartida, adota-se a experiência de ser obesa como fundante do discurso que emerge para a pesquisadora, a intérprete. A fenomenologia descrita por Gadamer (2015) nos auxiliou na interpretação.

Outra nutricionista em estado de obesidade, Diana, também expressa a força dos aprendizados sobre o comer na infância. Ela narra sobre o excesso alimentar rotineiro ao recordar que o consumo de alimentos na família não era determinado pela necessidade biológica, mas pela compensação antecipada pelo medo da falta de alimentos. Condição traumática da história de 
vida de seu avô. Para ela, o aprendizado científico não foi capaz de modificar o apreendido sobre comer em excesso:

Meu avô foi refugiado de guerra e passou por privação alimentar. Então, lá em casa era assim: você sempre podia comer mais. Eu lembro meu avô dizendo "eu vou morrer de barriga cheia”. Foi a educação que a gente teve. Criança comendo muito era bom, era saudável, era bonito ser criança gordinha. Quanto mais se tinha, mais podia comer. E adulta sou assim também. Um estudo que li esses dias dizia que os pais de crianças gordinhas não veem as suas crianças obesas. E comigo era assim... achava que estava tudo bem e não me via gorda. (Diana, 47 anos)

Outras narrativas, como as de Candice e Jéssica, que seguem abaixo, apresentam fragmentos de memória sobre o conflito alimentar:

Sempre fui grande desde menina (faz gesto com os braços arqueados em volta do corpo). Aos seis anos fiz uma cirurgia e minha mãe queria que eu comesse tudo que tinha comido até então. Comecei a comer e a engordar. (Candice, 57 anos)

Minha mãe dizia que com fome ou não, tinha de comer. Chegava o horário dos intervalos das refeições, tinha de comer. (Jéssica, 47 anos)

$\mathrm{Na}$ vivência dessas mulheres, a figura materna em vários momentos narrativos representa o eixo simbólico do comer - ou a orientação do comer - em demasia. Criam-se hábitos, escolhas e horários.

Os exemplos aqui apresentados demonstram que um sentido específico - como o comer em excesso - faz vínculo com o acontecimento, a obesidade. Ao recorrer aos estudos sobre memória na obra Los usos de la memoria, de Todorov (2013), cada indivíduo pode recordar o ultraje como único, ou o mais ofensivo. As nutricionistas recordam suas 'infâncias obesas' como experiências permanentes e sempre em confronto com o tempo presente. A infância parece determinar a obesidade, em suas falas. Assim, entre dois planos temporais, para elas nenhuma dieta pode remediar seus corpos em obesidades.

$\mathrm{Na}$ dimensão técnico-científica espera-se que sejam atrizes-tradutoras do enredo acadêmico, mas estas não conseguem aplicá-lo em suas vidas cotidianas. A nutricionista para demonstrar conhecimento, precisa marcá-lo em seu corpo de modo contundente. Entretanto, essa marca não aparece, pois seus corpos estão fora dos padrões antropométricos e de aceitação so- 
cial. Na intersubjetividade das narrativas dessas mulheres surge então, com frequência, o conflito que sentem na imposição do discurso normativo da nutrição. (FREITAS et al., 2012)

Suas narrativas dispõem sobre a separação entre o saber técnico científico e as escolhas alimentares pessoais, cuja intencionalidade não reduz o conflito e permanece uma dualidade entre obesidade e norma.

\section{"Tenho uma cabeça de gorda"}

A partir das experiências das mulheres entrevistadas, a obesidade é "lugar” de identidade, pois representa afetividade, gosto, desejo, na dimensão simbólica, subjetiva.

Entender como os sujeitos "[...] se vêem [sic] e determinam os fenômenos sociais que os envolvem contribui para a superação do paradigma centrado na díade saúde/doença”. (CASTRO, 2011, p. 10) Com essa possibilidade, o corpo obeso é construído de acordo com a história e a cultura dos sujeitos, conforme se apresenta a seguir, em alguns momentos selecionados das entrevistas:

Tenho uma cabeça de gorda que foi doutrinada para isso a vida toda. É muito difícil fazer dieta porque implica crenças, aquilo que você acredita, implica que você está muito estressado e acaba encontrando uma forma de fazer o mais fácil. E o que é o mais fácil?É você comer uma torta de chocolate. (Beatriz, zo anos)

Fiz a cirurgia de redução de estômago e foi bom para minha saúde. Sou hipertensa e depois disso reduzi a quantidade de medicamentos, melhorei da artrose. Mas confesso: é desesperador! Tudo continua como antes, cabeça gorda policiada por um estômago pequenino que não deixa os olhos crescerem muito ao ver alimentos. (Rita, 62 anos)

“Cabeça gorda” é a metáfora da gula. O efeito dos sentidos do desejo de comer em demasia, compulsivamente.

Para Beatriz, comer é uma construção sociocultural e a escolha do alimento se refere à praticidade: a comida pronta e industrializada, e o desejo que surge com a habitualidade. Não se contemplam dimensões físico-químicas e biológicas dos alimentos, mas outras que respondem aos sentidos de prazer e ansiedade. 
Um dos fatores condicionantes da escolha alimentar é motivado pelo estresse no trabalho, segundo algumas. A resposta pode ser uma "torta de chocolate" para aliviar a ansiedade. Este alimento é convencionalmente tido como não saudável pela ciência da saúde, obesogênico. Um ícone de satisfação e guloseima, na cultura ocidental.

A comida está envolvida em todos os melhores momentos de nossas vidas. Natal: comida. Uma criança nasce: você dá um "bem-nascido" (doce), no casamento: 'bem-casado' (pequeno bolo envolto em papel decorativo). Com isso a pessoa que te dá comida está dizendo que vocêe é importante para ela. (Beatriz, 3o anos)

Eu gosto de comer (sorri), e de fazer comida. [...] Lá em casa a alimentação sempre foi farta. Lembro que teve uma fase de crise financeira, mas a comida era sempre de primeira. A gente tem essa relação com a comida: almoço de família, sentar todo mundo junto, começar a comer cedo, e no domingo, só se levanta da mesa às três horas da tarde. (Amália, 33 anos)

Araniz e Comelles (2007, p. 26, tradução nossa) dizem que "comer também é um modo de se comunicar e se identificar com outras pessoas". Algumas narrativas fazem correspondências com escritos de Cecil Helman (2009, p. 56), sobre o valor simbólico da comida nas relações sociais. Também Otto e Ribeiro (2012) quando falam sobre a combinação entre alimentação e afetividade.

Nesse entendimento, Beatriz e Amália assumem que o momento de comer junto é celebração, pertencimento ao grupo social, expressão de amor e amizade. As escolhas alimentares centralizam o encontro humano como um texto a tornar possível o comer para além de uma disciplina da ciência.

\section{O sentido das escolhas alimentares e dietéticas}

As nutricionistas deste estudo vivem sedentárias, lutando contra a escassez de tempo para realizarem atividades físicas e consumir uma alimentação cotidiana mais elaborada. Com isso, suas escolhas alimentares são as mais rápidas, e mais encontradas no mercado. Em geral, são ricas em massas à base de farinhas, como pães, biscoitos e salgadinhos, doces - refrigerantes, brigadeiros e tortas -, gorduras - frituras - e pobres em vegetais - saladas. 
Essa nutrição obesogênica da sociedade contemporânea, é difícil de ser afrontada e provoca uma segregação entre o estilo de vida desejado e o possível para estas mulheres e tantas outras pessoas, certamente. A distância entre suas vivências e idealidades provocam sensações de fracasso, frustração, que repercutem na identidade profissional, evocando o sentimento de culpa pela ruptura da imagem corporal socialmente esperada, ou seja, nutricionistas antropometricamente normais nos padrões populacionais mundiais.

Entretanto, a cena cotidiana é outra. A subjetividade está entrelaçada aos conhecimentos científicos limitando sua aplicação.

Se eu estiver nervosa, estressada, vou na geladeira e como tudo que tiver pela frente. Não importa se tem gosto bom ou ruim. Eu como gelado. Como tudo. Fico puxando os pedaços das comidas em pé na frente da geladeira. [...] Comia pra compensar. (Diná, 49 anos)

A cena, aparentemente grotesca, representa um comportamento alimentar afetado por emoções. (DIEZ-GARCIA, 2012) Come-se excessivamente para compensar algo que se perde? Algo que se deseja e não pode alcançar?

Ademais desses sentidos, o comer faz relação com outras disposições corporais:

No meu período pré-menstrual tenho necessidade de chocolate, guloseimas, doces, frituras. Nesse período muda a demanda, o comportamento. Fico mais ansiosa, mais agitada, mais desnorteada. [...] E como é que encara isso de uma nutricionista? Profissional de saúde com o conhecimento técnico, teoria? Mas, na prática, você é um ser humano como qualquer outro [...] Então, internamente, a gente fica naquela eterna luta. (Sônia, 42 anos)

Ao falar de si em relação ao comer excessivo, a narrativa recorre à terceira pessoa como se o sujeito deslizasse o problema do eu para o outro. A estrutura da linguagem vai além da superfície dos sentidos, e por isso, comer para estas mulheres obesas pode significar compensar, não ter mais controle de si, pois já "não dá conta" de regular, ou de "fazer dieta".

Comer pode ser um recurso em situações adversas, como o estresse, que varia de acordo com a capacidade do sujeito em lidar com as dificuldades do cotidiano (DIEZ-GARCIA, 2012), como acontece na experiência de Diana. 
Abaixo, observa-se a vivência de Jéssica com repertórios divergentes do que propõe a ciência da saúde e o incômodo por ser socialmente vista como uma pessoa que não pode existir fora da regência da racionalidade biomédica:

Eu como muito quando estou com algum problema. Faço mesmo transferência para o alimento. [...] Quanto maior a carência emocional, quanto mais triste estou, mais eu como. Mas, nutricionista é proibida de comer. Existe o julgar. O prato da nutricionista tem que ter salada. Tudo no prato dela tem uma dimensão maior. (Jéssica, 47 anos)

Para Jéssica o conflito entre teoria e prática no campo da nutrição se torna evidente. Justifica as escolhas excessivas e qualitativamente inadequadas por mudanças do estado emocional. Essa também é a realidade de Diana, que revela um descontrole sobre si, um domínio do alimento quando há uma instabilidade no campo da subjetividade, conforme se vê:

Tenho uma compulsão. Quando eu disparo para comer, eu como mesmo! (Diana, 47 anos)

Há um conflito que marca a experiência dessas mulheres: a cobrança social - e delas mesmas - para seguir as recomendações científicas do bem comer, e as impossibilidades de executar o ordenamento das ciências naturais. As nutricionistas deste estudo ao "vivenciar" a obesidade em si, em seu corpo, "ferem" a normalidade, o esperado, a racionalidade cientifica.

Há uma lente nas relações sociais que atribui ao profissional de saúde a responsabilidade de cumprir o difundido discurso normativo do saudável. Nesse sentido, o nutricionista assume socialmente o lugar de "vitrine da saúde" - aquele profissional que além de prescritor de dietas emagrecedoras, consome comidas "leves”, sendo associado à prática de atividade física na perspectiva da promoção da saúde e prevenção de agravos.

Como representante da norma, não pode haver espaço para comportamentos incoerentes com essa orientação em suas vidas cotidianas. Com isso, as nutricionistas que têm excesso de peso e uma alimentação distante dos requisitos cientificamente determinados tendem a sofrer com um mal-estar subjetivo.

Elas vivem numa sociedade obesogênica, - e consomem fast foods, doces, refrigerantes, frituras, salgadinhos, chocolates, como visto antes - 
mas são cobradas pela sociedade a caber em medidas corporais enquadradas. Para elas, essa busca pelo corpo, que valida seu status profissional, tem sido tão esgotante quanto inatingível.

Diante da sensação de que sua aparência física inscreve informações sobre sua competência técnica, essas mulheres se sentem pressionadas a manejar sua dieta e vigiar continuamente suas escolhas. Nesse sentido, veem a obesidade como um estado contra o qual precisam lutar, para que o corpo atinja a métrica fixada como normal. (CANGUILHEM, 2011)

Sobre isso, as nutricionistas narraram acerca de suas tentativas de perda de peso, no intuito de buscar maior aceitação sócio profissional:

Já fiz de tudo: dieta da lua, do sol, do mar, do mundo, da peste, do juízo, da falta dele, de tudo que você possa imaginar! Todas essas (dietas) da moda aí eu já fiz. (Beatriz, 30 anos)

Jáfiz (dieta) de revista. (Eduarda, 37 anos)

Na minha casa você acha livro da dieta de Duncan, de South Beach, de Atkins, dos Pontos. Tudo que lança eu compro, leio e faço. (Candice, 57 anos)

Já tomei um shake (substituto de refeição) muito divulgado na mídia, mas parei porque não acreditei muito que podia dar resultado. (Rita, 62 anos)

Mesmo sabendo sobre orientações científicas para modulação das escolhas alimentares que possam contribuir para o cuidado das pessoas acometidas pela obesidade, as nutricionistas entrevistadas revelaram conhecer e utilizar diversas dietas, sem cunho científico comprovado, na tentativa de perder peso. Na experiência delas essas escolhas foram determinadas pelo sofrimento diante da ineficácia técnica. Define-se a racionalidade moderna como inaugural, ou seja, um modo de organizar o conhecimento teórico frente às questões sociais. (LUZ, 2004) Saber e mundo se encontram em conflito desde muito.

A compreensão da obesidade é incompleta. E é consenso na comunidade de saúde a sua gravidade e complexidade. $\mathrm{O}$ estado de obesidade abre espaço para surgimento de angústia que pesa na vida dessas mulheres entrevistadas. E considerando a aflição que invade a existência dessas nutricionistas e possivelmente a outras pessoas sem formação acadêmica na área da saúde também acometidas pela obesidade. Pode-se pensar em ele- 
ger teorias das ciências humanas e sociais para colaborar no alargamento dos limites biomédicos para o tratamento desta questão que toca o mundo das subjetividades. Como vimos antes, elegem-se autores da fenomenologia para uma aproximação da existência obesa dessas nutricionistas colaboradoras desse estudo.

\section{Considerações finais}

Constata-se que há um forte conflito entre escolhas alimentares de nutricionistas obesas, seus discursos técnico-científicos referenciados na formação acadêmica em nutrição e o contexto de uma sociedade obesogênica. O estudo tenta mostrar a importância do tema que deve reunir as ciências da saúde e as sociais e humanas para que se possa continuar esta investigação de modo mais profundo.

A aflição das nutricionistas capaz de modificar suas escolhas alimentares indica a necessidade de (re)elaboração de cenas da vida cotidiana para obterem novos sentidos cognitivos representativos do ato de comer.

Como profissionais da saúde que cuidam da alimentação, elas carregam um paradoxo: de um lado, o desejo de seguir as normas técnicas que possibilitam preservar a saúde, e de outro o sentimento de "derrota” diante de sua própria condição obesa cujos condicionantes sociais são perversos. Nessa perspectiva, o estudo permite pensar a obesidade enquanto uma questão social complexa que envolve tessituras entre corpo, saúde, alimentação e sociedade.

A obesidade precisa ser considerada um assunto ético, diante do sofrimento humano que ela provoca. As narrativas das nutricionistas com obesidade sobre as dificuldades de modulação das escolhas alimentares, alinhadas às normativas científicas, convidam a uma sensibilização do olhar sobre a vida contemporânea e para os aspectos socioantropológicos da alimentação que podem explicar a presença dessa condição humana.

\section{Referências}

ARANIZ, M. G.; COMELLES, J. M. (Coord.). No comerás: narrativas sobre comida, cuerpo y género en el nuevo milenio. Barcelona: Icaria editorial, 2007 . 
BADZIAK, R. P. F.; MOURA, V.E.V. Determinantes sociais da saúde: um conceito para efetivação do direito à saúde. Revista de Saúde Pública de Santa Catarina, Florianópolis, v. 3, n. 1, p. 69-79, jan./jun. 2010.

BERTAUX, D. Los relatos de vida em el análises Social. In: LOZANO, J. E. A. Historia oral. Ciudad de México: Instituto Mora: Universidad Autónoma Metropolitana, 1993·p. 136-148.

BOURDIEU, P. O poder simbólico. Rio de Janeiro: Bertrand Brasil; Lisboa: Difel, 1989. (Série Memória e Sociedade).

BRASIL. Ministério da Saúde. Agência Nacional de Saúde Suplementar. Vigitel Brasil 2015 Saúde Suplementar: vigilância de fatores de risco e proteção para doenças crônicas por inquérito telefônico. Brasília, DF, 2017.

BRASIL. Ministério da Saúde. Secretaria de Atenção à Saúde. Diretrizes do NASF: núcleo de apoio a saúde da família. Brasília, DF, 20og. (Série A. Normas e manuais técnicos). (Cadernos de Atenção Básica, n. 27).

BRASIL. Ministério da Saúde. Secretaria de Atenção à Saúde. Departamento de Atenção Básica. Política nacional de alimentação e nutrição. Brasília, DF, 2012. (Série B. Textos Básicos de Saúde).

BRASIL. Ministério da Saúde. Secretaria de Atenção à Saúde. Departamento de Atenção Básica. Política nacional de práticas integrativas e complementares no SUS: atitude de ampliação de acesso. Brasília, DF, 20o6. (Série B. Textos Básicos de Saúde).

BRASIL. Ministério da Saúde. Secretaria de Vigilância em Saúde. Secretaria de Atenção à Saúde. Política nacional de promoção da saúde. 3. ed. Brasília, 201o. (Série B. Textos Básicos de Saúde). (Série Pactos pela Saúde 20o6, v. 7).

BRASIL. Obesidade atinge mais da metade da população brasileira, aponta estudo. 2013. Disponível em: <http://www.brasil.gov.br/saude/2013/o8/obesidade-atingemais-da-metade-da-populacao-brasileira-aponta-estudo $>$. Acesso em: 03 ago. 2017 .

CANGUILHEM, G. O normal e o patológico. Tradução de Maria Thereza Redig de Carvalho Barrocas. 7. ed. Rio de Janeiro: Forense Universitária, 2011.

CASTRO, H. C. Representações sociais da obesidade para mulheres em situações de pobreza. 2011. 44 f. Monografia (Graduação em Nutrição) - Faculdade de Medicina, Universidade Federal do Rio Grande do Sul, Porto Alegre, 2011. 
CONSELHO FEDERAL DE NUTRICIONISTAS CFN. Resolução CFN n ${ }^{\circ} 3^{80}$, de 28 de dezembro de 2005. Dispõe sobre a definição das áreas de atuação do nutricionista e suas atribuições, estabelece parâmetros numéricos de referência, por área de atuação, e dá outras providências. Diário Oficial [da] República Federativa do Brasil, Brasília, DF, 10 jan. 20o6. Seção 1, p. 66-71.

CONTRERAS, J. Teorias Antropológicas sobre Alimentação. In: CONTRERAS, J.; GRACIA, M. Alimentação, sociedade e cultura. Tradução de Mayra Fonseca e Bárbara AtieGuidalli. Rio de Janeiro: FIOCRUZ, 2011. p. 25-107.

COMISSÃO NACIONAL SOBRE OS DETERMINANTES SOCIAIS DA SAÚDE - CNDSS. Carta aberta aos candidatos à Presidência. Radis: comunicação em saúde, Rio de Janeiro, n. 49, set. 2oo6. Disponível em: <http://www6.ensp. fiocruz.br/radis/revista-radis/49/reportagens/comissao-nacional-sobredeterminantes-sociais-da-saude>. Acesso em: 14 dez. 2017.

DIEZ-GARCIA, R. W. Mudanças Alimentares: Implicações Práticas, Teóricas e Metodológicas. In: DIEZ-GARCIA, R. W.; CERVATO-MANCUSO, A. M. (Coord.). Mudanças alimentares e educação nutricional. Rio de Janeiro: Guanabara Koogan, 2012.

FREITAS, M. C. S. et al. Hábitos alimentares e os sentidos do comer. In: DIEZGARCIA, R. W.; CERVATO-MANCUSO, A. M. (Coord.). Mudanças alimentares e educação nutricional. Rio de Janeiro: Guanabara Koogan, 2012.

FREITAS, M. C. S.; MINAYO, M. C. S.; FONTES, G. A.V. Sobre o campo da alimentação e nutrição na perspectiva das teorias compreensivas. Ciência \& Saúde Coletiva, Rio de Janeiro, v. 16, n. 1, p. 31-38, jan. 2011.

GADAMER, H.-G. O caráter oculto da saúde. Petrópolis, RJ: Vozes, 2006.

GADAMER, H.-G. Verdade e método. Tradução de Flávio Paulo Meurer. 15. ed. Petrópolis, RJ: Vozes; Bragança Paulista, SP: EdUFS, 2015.

GOFFMAN, E. Estigma: la identidad deteriorada. Buenos Aires: Amorrortu, 1993 .

HELMAN, C. G. Dieta e nutrição. In: HELMAN, C. G. Cultura, saúde e doença. Tradução de Ane Rose Bolner. 5. ed. Porto Alegre: Artmed, 2009.

LUZ, M. T. Natural, racional, social: razão médica e racionalidade científica moderna. 2. ed. São Paulo: Hucitec, 2004.

MOTTA, D. G.; MOTTA, C. G.; CAMPOS, R. R. Teorias psicológicas da fundamentação do aconselhamento nutricional. In: DIEZ-GARCIA, R. W.; CERVATO-MANCUSO, A. M. (Coord.). Mudanças alimentares e educação nutricional. Rio de Janeiro: Guanabara Koogan, 2012. 
OTTO, A. F. N.; RIBEIRO, M. A. Unidos em torno da mesa: a dinâmica familiar na obesidade. Estudos de Psicologia, Natal, v. 17, n. 2, p. 255-263. maio/ago. 2012.

SILVA, D. O. Reflexões conceituais e de profissionais de saúde sobre a promoção da alimentação saudável. In: DIEZ-GARCIA, R. W.; CERVATO-MANCUSO, A. M. (Coord.). Mudanças alimentares e educação nutricional. Rio de Janeiro: Guanabara Koogan, 2012.

TODOROV, T. Los usos de la memoria. Buenos Aires: Museo de la Memoria y los Derechos Humanos, 2013. (Colección Signos de la Memoria).

WORLD HEALTH ORGANIZATION - WHO. Overwheigth and obesity. [201-]. Disponível em: <http:/www.who.int/gho/ncd/risk_factors/overweight_text/ en/>. Acesso em: o3 ago. 2017. 